\title{
MORTALIDADE EM MIGRANTES - JAPONESES RESIDENTES NO MUNICÍPIO DE SÃO PAULO, BRASI, 1990 *
}

\author{
Sabina L. D. Gotlieb **
}

GOTLIEB, S. L. D. Mortalidade em migrantes - japoneses residentes no Município de São Paulo, Brasil, 1980. Rev. Saúde públ., S. Paulo, 24:453-67, 1990.

RESUMO: Objetivou-se comparar o padrăo de mortalidade dos imigrantes japoneses (isseis) e de seus descendentes (nisseis/sanseis), residentes no Município de São Paulo, com o do Japão, local de origem, e o do Município de São Paulo, local de destino destes migrantes, em 1980. Os principais grupos de causas de morte foram basicamente semelhantes para estas populações, sendo que os maiores coeficientes padronizados foram os de São Paulo. A única exceção foi o risco de morrer por neoplasmas, maior no Japão. Os isseis (ambos os sexos) apresentaram riscos com valores intermediários para as Doenças das Glândulas Endócrinas e do Metabolismo e para as Doenças do Aparelho Respiratório; para as isseis, o risco de morrer por Doenças do Aparelho Circulatório também foi intermediário. Nos demais grupos de causa, os isseis apresentaram os menores riscos de morrer. Os riscos de morrer por Câncer do Estômago, Mama e Próstata, Diabetes Mellitus, Doenças Isquêmicas do Coração, Doenças Cerebrovasculares, Homicídios e Suicídios permitiram concluir que os isseis estão paulatinamente afastando-se do padrão de morte do Japão e tendendo ao de São Paulo. Surgem hipóteses de que estejam ocorrendo mudanças socio-culturais nos migrantes e haja predominância de atuação de fatores de risco ambientais e não de genéticos, na incidência e na mortalidade desses agravos à saúde.

DESCRITORES: Mortalidade. Causa de Morte. Grupos étnicos. Japão, etnologia.

\section{1 - INTRODUÇÃO}

Morris ${ }^{15}$ caracterizou os usos da epidemiologia, tais como o de contribuir para a definição da amplitude dos problemas de saúde/doença de uma comunidade, avaliar hipóteses sobre a causalidade das doenças e suas seqüelas e relacioná-las às características das pessoas e de seu ambiente.

Pela sua importância epidemiológica, são freqüentes estudos que se preocupam em mostrar diferenças de risco de morrer e adoecer entre populações de nativos e de imigrantes residentes em uma mesma área. Tais estudos permitem investigar possíveis fatores presentes e atuantes no aparecimento do agravo, isto é, induzem ao esclarecimento se seriam fatores ligados ao hospedeiro ou ao novo ambiente que estariam atuando. Reid ${ }^{23} \mathrm{diz}$ que movimentos migratórios permitem elucidaçoes, quer sobre o impacto que tais mudanças podem acarretar sobre a saúde dos indivíduos, quer sobre a permanência, nos migrantes, de efeitos residuais obtidos em uma infância passada, em um dado ambiente, mesmo após a mudança para um novo local.

Contrastes detectados entre os nativos e os migrantes são parciais; para globalizar o quadro epidemiológico, a experiência dos migrantes deve ser comparada às prevalentes tanto no local de destino dos migrantes, como onde nasceram.

Acatando estas premissas, análises da mortalidade em migrantes foi realizada ${ }^{6}$, mostrando que 0 padrão de mortalidade dos japoneses e seus descendentes residentes no Município de Săo Paulo, em 1968, situava-se em nível intermediário entre os do Japão e do Município, considerando a Mortalidade Proporcional. Tal constatação permitiu que indagaç̋̃es surgissem no sentido do possível papel preponderante de fatores genéticos, algumas vezes, e de fatores ambientais, em outras, considerando a interação desses fatores no surgimento de agravos à saúde.

Dispor de dados do $9^{9}$ Recenseamento Geral do Brasil de 1980, sobre a distribuição dos nascidos no Japão e residentes no Município de São Paulo, foi um estímulo para que fosse planejado um novo estudo sobre coeficientes de mortalidade. $O$ conhecimento das intensidades com que os agravos estão atuando, nas populaçōes de estudo, tornar-se-ia em subsídio para melhor enunciar hipóteses de caráter epidemiológico.

O presente estudo objetiva descrever e comparar a mortalidade segundo as principais causas básicas no Japão, no Município de São Paulo e nos migrantes

\footnotetext{
* Resumo da tese de livre-docência: "Mortalidade em migrantes: japoneses residentes no Município de São Paulo", apresentada à Faculdade de Saúde Pública da USP, em 1988.

* Departamento de Epidemiologia da Faculdade de Saúde Pública da Universidade de São Paulo - Av. Dr. Arnaldo, 715 - 01255 - São Paulo, SP - Brasil.
} 
japoneses (isseis) e sêus descendentes (nisseis/ sanseis), residentes no Município, em 1980.

\section{2 - MATERIAL E MÉTODO}

\subsection{Populações de Estudo}

\subsubsection{Japão}

A população estudada foi constituída por residentes no Japão em $1^{2}$ de julho de 1980 e estimada (método aritmético) a partir dos censos de primeiro de outubro de 1975 e $1980^{25}$. A sua constituição segundo sexo e grupos etários seguiu as percentagens calculadas na estrutura populacional do censo de 1980.

Os óbitos correspondem aos ocorridos em 1980 e foram coletados na publicação "Vital Statistics1980: Japan"10, apresentando-os segundo sexo, idade e causa básica, classificada segundo a lista de categorias de três algarismos da $9^{\mathrm{a}}$ Revisão da Classificação Internacional de Doenças (CID) ${ }^{17}$.

\subsubsection{Isseis}

Constituída por nascidos no Japão e que emigraram para o Brasil, refere-se aos isseis residentes no Município de São Paulo, em $1^{2}$ de julho de 1980. Foram usadas tabulações especiais do $9^{\circ}$ Recenseamento Geral do Brasil, que apresentavam a distribuição segundo sexo e idade.

Para determinar a população em $1^{2}$ de julho de 1980 , foi necessário incorporar àquela recenseada ( $1^{8}$ de setembro de 1980), nos respectivos sexos e faixas etárias, os 6 bitos de isseis ocorridos de $1^{2}$ de julho a 31 de agosto de 1980, apurados neste trabalho. Esta foi a solução eleita para se estimar, admitindo-se que no período não houve movimento migratório.

Os óbitos correspondem aos ocorridos no período de 1 - de janeiro de 1979 a 31 de dezembro de 1981 . Com a permissão da Fundação Sistema Estadual de Análise de Dados Estatísticos (FSEADE), as informaçōes foram selecionadas das declarações de óbito registradas no Município de São Paulo, entre janeiro de 1979 e janeiro de 1982 (172.000).

Para pertencerem a este grupo, as declarações tinham preenchidas as variáveis naturalidade, com a modalidade: japonesa ou Japão e residência, com a designação: Município de São Paulo. Satisfizeram aos requisitos 2.346 declarações de óbito.

\subsubsection{Nisseis/Sanseis}

População formada por descendentes de japoneses nascidos no Brasil (sem levar em conta a geração), residentes no Município de São Paulo, em $1^{2}$ de julho de 1980 . Entretanto, foi impraticável a sua obtenção.
Os óbitos são os de descendentes de japoneses, residentes no Município, ocorridos nos anos de 1979, 1980 e 1981.

A informação, tal qual dos isseis, foi obtida de declarações de óbito. Para pertencerem a esta população, as declarações precisavam satisfazer aos requisitos: ter nascido no Brasil e o nome e/ou sobrenome do pai e/ou da mãe do falecido ser de origem japonesa. Foram selecionadas 1.322 declarações.

\subsubsection{Município de São Paulo}

O total de residentes no Município de São Paulo, em primeiro de julho de 1980, foi obtido no Anuário Estatístico do Estado de São Paulo. ${ }^{1}$ Para compor a estrutura populacional segundo sexos e grupos etários quinqüenais, foi calculada e adotada a composição percentual existente no momento do censo.

Os óbitos são os de residentes do Município de São Paulo, ocorridos em 1980. As informaçōes foram compiladas de fichas microfilmadas da FSEADE.

\subsection{Variáveis de Estudo}

As variáveis consideradas na análise são: sexo, faixa etária, causa básica de morte e população de estudo.

As faixas etárias formadas são qüinqüenais, sendo que a última engloba as idades de 85 anos e mais. Tal limite foi definido em função dos dados secundários disponíveis.

A apresentação da mortalidade segundo causa básica é feita segundo categorias (três algarismos) ou agrupamentos de causas ou capítulos da CID, dependendo do interesse.

\subsection{Métodos}

O tratamento dos dados consistiu no cálculo de: mortalidade proporcional, coeficientes gerais e específicos de mortalidade, brutos e padronizados ${ }^{13}$. Em relação aos isseis, foram calculados coeficientes médios para 1979/1981, evitando distorções, dado o pequeno número de mortes, e eliminando os efeitos eventuais. Para a padronização dos coeficientes foram estimadas as populaçōes padrão, segundo Jowett citado por Laurenti e col. ${ }^{13}$ que consistiu na média harmônica dos estratos das três populações.

Para Fleiss ${ }^{3}$, coeficiente e probabilidade são sinônimos, porém, para Kleinbaum e col. ${ }^{11}$, risco e coeficiente são conceitualmente distintos. Coeficiente ou taxa, sendo medida de frequiência, representa o potencial instantâneo de mudança no "status" de uma população; risco é uma medida de 
probabilidade de ocorrência de um evento, portanto adimensional. O uso comum dos diferentes conceitos, para designar ocorrência de eventos, vem do fato de que a relação entre riscos e coeficientes de mesmos eventos é conhecida, variando ambos no mesmo sentido. Na linguagem comum, os termos têm sido usados alternativamente. Para facilidade de expressão, no presente trabalho, ambos os termos serão usados, indiferentemente.

\section{3 - RESULTADOS E DISCUSSÃO}

\subsection{Populações de Estudo}

\subsubsection{Japão}

A população do Japão compreende 116.667 .562 habitantes, em 1980, sendo que $49,2 \%$ são homens. A estrutura por sexo e idade é a de população que passou por transição demográfica, devida a baixa natalidåde e redução dos riscos de morrer em jovens e adultos, tendo grande contingente de idosos. Ambos os sexos apresentam o grupo de 30 a 34 anos como o modal, representando o "baby-boom" ocorrido entre 1945 e 1949, após a Segunda Guerra Mundial, e início de planejamento familiar, em 1950, incentivado pelas autoridades governamentais ${ }^{12}$.

Em 1982, a esperança de vida masculina foi 74,2 anos e 79,7 anos, a feminina. Tais valores são os mais altos, mundialmente. $O$ ganho na vida média foi excepcional e é fruto de aprimoramento do nível socio-econômico da população e ações de caráter de saúde pública e de assistência médica 26.

\subsubsection{Isseis}

A corrente migratória de japoneses para o Brasil iniciou-se em 1908, com grandes contingentes concentrando-se antes da Segunda Guerra (1925 a 1934) e logo após a mesma. E importante do ponto de vista de migração visto que no censo de 1970 $12,35 \%$ dos estrangeiros residentes no Brasil tinham vindo do Japão e a grande maioria localizou-se no Estado de São Paulo (116.566 isseis) ${ }^{14}$. Os dados de $1980^{4}$ informam haver 115.118 japoneses no Brasil e praticamente $80 \%$ estabeleceram-se no Estado de São Paulo.

Em primeiro de julho de 1980, a população de isseis foi estimada em 50.059 habitantes e apresenta uma estrutura etária formada principalmente por adultos e idosos. A razão de masculinidade é de 1.112 homens para mil mulheres, indo ao encontro da referida predominância masculina em movimentos migratórios.

\subsubsection{Município de São Paulo}

Formada de 8.444 .460 habitantes, a população do Município de São Paulo é composta por $48,9 \%$ de homens. A estrutura por sexo e faixa etária representa pirâmide típica de país em desenvol- vimento, com base relativamente larga e ápice afilado. A esperança de vida é 63,6 anos para os homens e 70,8 anos para as mulheres (respectivamente, $14 \%$ e $11 \%$ menor do que as do Japão). A faixa etária modal é a de menores de 5 anos, em ambos os sexos: é a mais jovem entre as três populaçðes de estudo (Tabela 1).

\subsection{Mortalidade}

Os coeficientes de mortalidade padronizados são, no Japão, 17,8 por mil homens e 14,3 por mil mulheres; em São Paulo, 26,2 por mil homens e 19,8 por mil mulheres e entre os isseis, 16,3 por mil homens e 14,3 por mil mulheres.

Verifica-se então que, controlada a diferença de estrutura etária, o maior coeficiente de mortalidade é dos residentes em São Paulo, sendo que, entre os homens, seu valor é $47 \%$ maior do que o do Japão e $61 \%$ maior do que o dos isseis. O coeficiente no Japão é $10 \%$ maior do que o dos isseis.

Quanto às mulheres, o coeficiente em São Paulo é, aproximadamente, $49 \%$ maior daqueles apresentados tanto pelas residentes no Japão como isseis, cujos valores são semelhantes.

\subsubsection{Mortalidade proporcional}

No Japão, em 1980, os principais grupos de cau-

\section{TABELA 1}

Parâmetros etários populacionais segundo sexo e populaçoes de estudo, 1980.

\begin{tabular}{|c|c|c|c|}
\hline \multirow{2}{*}{$\begin{array}{c}\text { Sexo/ } \\
\text { Parâmetros } \\
\text { Etários }\end{array}$} & \multicolumn{3}{|c|}{ Populaçōes de estudo } \\
\hline & Isseis & Japão* & $\begin{array}{l}\text { Município de } \\
\text { São Paulo** }\end{array}$ \\
\hline
\end{tabular}

Homens

$\begin{array}{lccc}\begin{array}{l}\text { idade média } \\ \text { idade mediana }\end{array} & 52,8 & 32,9 & 26,5 \\ \text { faixa modal } & 54,5 & 31,8 & 23,9 \\ & 55 \text { a } 59 & 30 \text { a } 34 & <5 \\ \%<15 \text { anos } & 2,4 & 24,5 & \\ \% 15 \text { a } 49 \text { anos } & 37,1 & 53,8 & 30,9 \\ \% 50 \text { anos e mais } & 60,5 & 21,7 & 56,6 \\ \end{array}$

Mulheres

\begin{tabular}{lccc} 
idade média & 54,0 & 35,0 & 27,8 \\
$\begin{array}{l}\text { idade mediana } \\
\text { faixa modal }\end{array}$ & 55,8 & 33,6 & 24,7 \\
& 50 a 54 & 30 a 34 & $<5$ \\
$\begin{array}{l}\text { \% } 15 \text { anos } \\
\% 15 \text { a } 49 \text { anos }\end{array}$ & 2,6 & 22,6 & 29,1 \\
$\% 50$ anos e mais & 65,7 & 51,5 & 56,2 \\
\hline
\end{tabular}

Fonte: * Statistics Bureau Prime Minister's Office 25 (1982).

* * Fundação SEADE' (1981). 
sas são as Doenças do Aparelho Circulatório, os Neoplasmas. No sexo masculino, seguem-se as Causas Externas de Lesões, Doenças do Aparelho Respiratório e Doenças do Aparelho Digestivo. Para as mulheres, tem-se Doenças do Aparelho Respiratório, Causas Externas e Doenças do Aparelho Digestivo.

Para São Paulo, em 1980, os principais são Doenças do Aparelho Circulatório, as Causas Externas para os homens e Neoplasmas para as mulheres. A seguir, no sexo masculino, têm-se Doenças do Aparelho Respiratório, Neoplasmas e Doenças Infecciosas e Parasitárias, e para as mulheres, Doenças do Aparelho Respiratório, Algumas Afecções Originadas no Período Perinatal e Doenças Infecciosas e Parasitárias. É digno de nota estas últimas ainda estarem entre as principais e verifica-se que um dos fatores é a alta mortalidade por doenças infecciosas intestinais $(52,5 \%$ dessas mortes), mostrando a existência de problemas ligados ao saneamento e à desnutrição, em São Paulo.

O padrão de mortalidade dos isseis é semelhante ao do Japão e a ordenação apresenta Doenças do Aparelho Circulatório, Neoplasmas, Doenças do A parelho Respiratório, Causas Externas (sexo masculino) e Doenças das Glândulas Endócrinas (sexo feminino) e Doenças do Aparelho Digestivo.

Entre os nisseis/sanseis, no período de 1979 a 1981 , as principais causas de morte foram as
Doenças do Aparelho Circulatório, Algumas Afecções Originadas no Período Perinatal, Causas Externas de Lesões, Neoplasmas e Doenças do Aparelho Respiratório. No sexo feminino, as principais causas foram as Afecções Originadas no Período Perinatal, Doenças do Aparelho Circulatório, Neoplasmas, Causas Externas de Lesões e Doenças do A parelho Respiratório.

Sintetizando as diferenças entre as quatro populações, as Tabelas 2 e 3 expõem os principais grupos de causas.

Analisando a mortalidade, não mais considerando capitulos da CID, mas tendo em vista agrupamentos e/ou categorias, surgem comportamentos distintos nas populações de estudo.

Neoplasias Malignas - Considerando-se a sede anatômica do tumor, para os óbitos do Japão e isseis, a principal é o estômago $(7,9 \%$ e $7,8 \%$ dos óbitos masculinos, respectivamente). Este agravo assume 1,8\% dos óbitos de São Paulo e 3,3\% de nisseis/sanseis. No sexo feminino esteve presente em $5,9 \%$ dos óbitos do Japão, 4,3\% dos isseis. Relativamente a São Paulo, observa-se em 1,5\% e em $2,5 \%$ dos 6 bitos das nisseis/sanseis.

Chama a atenção a mortalidade proporcional por câncer de próstata, pois há diferença acentuada entre os óbitos do Japão, dos isseis e São Paulo, representando, respectivamente, $1,9 \%, 5,6 \%$ e $6,8 \%$ do total de óbitos.

\section{TABELA 2}

Principais causas básicas de morte, no sexo masculino, segundo ordenação e populações de estudo, 1980*

\begin{tabular}{|c|c|c|c|c|}
\hline Ordenação & Japão & Isseis* & $\begin{array}{c}\text { Nisseis** } \\
e \\
\text { Sanseis }\end{array}$ & $\begin{array}{l}\text { Munićpio } \\
\text { de } \\
\text { São Paulo }\end{array}$ \\
\hline $1^{a}$ causa & $\begin{array}{l}\text { Ap. Circulatório } \\
(40,2 \%)\end{array}$ & $\begin{array}{l}\text { Ap. Circulatório } \\
(45,2 \%)\end{array}$ & Ap. Circulatório & $\begin{array}{c}\text { Ap. Circulatório } \\
(30,8 \%)\end{array}$ \\
\hline $2^{2}$ causa & $\begin{array}{c}\text { Neoplasmas } \\
24,8 \%\end{array}$ & $\begin{array}{c}\text { Neoplasmas } \\
(22,2 \%)\end{array}$ & $\begin{array}{l}\text { Afecções Período } \\
\text { Perinatal }(19,6 \%)\end{array}$ & $\begin{array}{c}\text { Externas } \\
(14,0 \%)\end{array}$ \\
\hline $3^{a}$ causa & $\begin{array}{c}\text { Externas } \\
(9,2 \%)\end{array}$ & $\begin{array}{c}\text { Aparelho respiratório } \\
(10,7 \%)\end{array}$ & $\begin{array}{l}\text { Externas } \\
(16,9 \%)\end{array}$ & $\begin{array}{c}\text { Aparelho Respiratório } \\
(12,7 \%)\end{array}$ \\
\hline $4^{a}$ causa & $\begin{array}{l}\text { Aparelho respiratório } \\
\qquad(8,4 \%)\end{array}$ & $\begin{array}{c}\text { Externas } \\
(6,1 \%)\end{array}$ & $\begin{array}{c}\text { Neoplasmas } \\
(12,0 \%)\end{array}$ & $\begin{array}{l}\text { Neoplasmas } \\
\quad(11,4 \%)\end{array}$ \\
\hline $5^{\mathrm{a}}$ causa & $\begin{array}{l}\text { Ap. digestivo } \\
(6,1 \%)\end{array}$ & $\begin{array}{l}\text { Ap. digestivo } \\
\qquad(5,8 \%)\end{array}$ & $\begin{array}{l}\text { Ap. respiratório } \\
(9,1 \%)\end{array}$ & $\begin{array}{c}\text { Infecciosas Parasitárias } \\
(8,0 \%)\end{array}$ \\
\hline
\end{tabular}

* Entre parênteses, valores da mortalidade proporcional (\%).

* * Refere-se ao período $1979 / 1981$. 
Diabetes Mellitus - Entre os homens, a mortalidade proporcional por Diabetes é igual a $1 \%$ no Japão, 2,1\% entre os isseis, $1,8 \%$ entre os nisseis/ sanseis e 1,8\% em São Paulo. Para as mulheres, representam 1,3\% no Japão, 3,5\% dos 6́bitos de São Paulo, $5 \%$ entre as mortes das isseis e $2,8 \%$ entre as das nisseis/sanseis.

Doenças do Aparelho Circulatorio - Considerando-se agrupamentos dentre as Doenças do Aparelho Circulatório, o comportamento detectado, em $1968^{6}$, mantém-se no atual estudo. Assim, em 1980 , para os homens, as Doenças Isquêmicas do Coração (DIC) representaram 6,9\% dos óbitos do Japão, 12,4\%, 16,7\% e 7,1\% dos óbitos de São Paulo, de isseis e de nisseis/sanseis, respectivamente. Por sua vez, os óbitos por Doenças Cerebrovasculares (DCV) foram responsáveis por 20,9\% dos óbitos do Japão, 8,3\% de Săo Paulo, 18,5\% de isseis e 7,3\% de nisseis/sanseis. Infere-se, portanto, que para os japoneses e seus descendentes as DCV continuam sendo mais importantes que as DIC.

No sexo feminino, acentua-se a diferença, pois, no Japão, 24,3\% dos seus óbitos apresentam como causa básica as DCV, e 6,5\%, as DIC; essas causas estão presentes em $22,6 \%$ e $17 \%$ dos óbitos das isseis, respectivamente. Para as residentes em São Paulo, as DCV são responsáveis por $11,3 \%$ dos óbitos e as DIC por 12,1\%. Entre as nisseis/sanseis, as DCV são também mais importantes, apresentam-se em $9,7 \%$ dos óbitos e as DIC, como causa básica de morte, perfazem $4,4 \%$.

Causas Externas de Lesōes e Envenenamentos - A diferença principal entre as populaçōes estudadas reside na frequêencia dos homicídios e dos suicídios. No Japão, os suicídios suplantam os homicídios, em ambos os sexos, sendo a mortalidade proporcional nos homens igual a $3,2 \%$ e $0,2 \%$, e entre as mulheres, $2,3 \%$ e $0,1 \%$. Nos homens de São Paulo, a situação é inversa, há mais homicídios (4\%) do que suicídios $(0,8 \%)$ e as proporções são iguais para as mulheres $(0,6 \%)$.

Estas diferenças podem ser atribuídas à atuação de fatores culturais, de um lado, e de fatores de risco ambientais, de outro, sendo conhecido o traço cultural de aceitação e valorização do suicídio, no Japão" ao mesmo tempo, é conhecida a violência urbana de São Paulo.

As mortes dos isseis mostram a possível transformação que os migrantes experimentam, abandonando valores culturais e deixando de se expor a riscos do local de origem e adotando os do local de destino. Pelos resultados, no sexo masculino $(0,7 \%$ para suicídio e $0,6 \%$ para homicídio), pode ser pensado em um possível afastamento do padrão do Japão com conseqüente semelhança aos de São Paulo. Já os seus descendentes (nisseis/sanseis) assemelham-se mais à população que acolheu seus pais imigrantes, isto é, $3,5 \%$ dos óbitos masculinos têm como causa básica o homicídio, e 2,4\%, o suicídio; no sexo feminino, têm-se, $1,1 \%$ e $0,9 \%$, respectivamente.

Os acidentes de trânsito de veículos a motor representaram $4,8 \%$ do total de óbitos masculinos de São Paulo e 2,1\% dos femininos; no Japão, foram $2,2 \%$ e $0,9 \%$, respectivamente. Os isseis sofrem também ação dessas causas ( $3 \%$ das mortes masculinas e $1,1 \%$ das femininas) e os nisseis/sanseis apresentam $6,7 \%$, para os homens, e $6,1 \%$, para as mulheres. Esta causa, para os nisseis/sanseis, só é menos importante do que algumas ligadas ao período perinatal (com cerca de $12 \%$ das mortes).

\subsubsection{Coeficientes de Mortalidade}

Detectadas as principais causas de mortalidade, cabe a análise do risco de morrer e assim poder aquilatar as diferenças fundamentais entre as populações do Japão, de São Paulo e de isseis.

Para as principais causas de morte, em ambos os sexos, os coeficientes padronizados de mortalidade são sempre maiores para São Paulo (Tabela 4). As únicas exceçð̃es são, no sexo masculino, Weoplasmas (valores próximos para o Japão e São Paulo) e no feminino, as Causas Externas.

Os isseis apresentam, comparativamente, coeficientes em nível intermediário, para as Doenças das Glândulas Endócrinas (Capítulo III da CID), Doenças do Aparelho Respiratório e Causas Externas; as mulheres também têm valor intermediário para Doenças do Aparelho Circulatório. Para as demais causas, os menores coeficientes padronizados são os dos isseis.

Comparando as três populações femininas, chama a atenção o aparecimento das Afecçōes do Período Perinatal como a quarta principal causa, em São Paulo (coeficiente de 4,4 por dez mil mulheres). Ao ser calculado com a população realmente exposta a este risco, isto é, a dos nascidos vivos, torna-se 17,4 por mil nascidos vivos femininos; tal valor, bastante alto, mostra a existência de precárias condições de saúde e de assistência à saúde materno-infantil em São Paulo, em 1980.

Neoplasias Malignas - Para melhor detectar as diferenças de risco de morrer por Neoplasias Malignas entre as três populações de análise, podem ser destacadas algumas localizações específicas (Tabela 5). A mais importante sede de tumor é o estômago, tanto para os residentes no Japão como para os isseis. Para as residentes em São Paulo, o coeficiente padronizado por câncer de mama suplanta aquele por câncer do estômago, e para os homens, em São Paulo, é o pulmão a principal sede.

A taxa padronizada de morrer por câncer do estômago entre isseis é $14 \%$ menor do que no Japão e, em São Paulo, é 50\% e 40\% menor que as no Japão 
TABELA 3

Principais causas básicas de morte, no sexo feminino, segundo ordenação e populações de estudo, 1980*

\begin{tabular}{|c|c|c|c|c|}
\hline Ordenação & Japão & Isseis* & $\begin{array}{c}\text { Nisseis** } \\
e \\
\text { Sanseis }\end{array}$ & $\begin{array}{l}\text { Município } \\
\text { de } \\
\text { São Paulo }\end{array}$ \\
\hline $1^{\prime}$ causa & $\begin{array}{c}\text { Aparelho Circulatório } \\
(46,2 \%)\end{array}$ & $\begin{array}{c}\text { Aparelho Circulatório } \\
(52,9 \%)\end{array}$ & $\begin{array}{l}\text { Afecções Período } \\
\text { Perinatal }(20,3 \%)\end{array}$ & $\begin{array}{c}\text { Aparelho Circulatório } \\
(37,6 \%)\end{array}$ \\
\hline $2^{\prime}$ causa & $\begin{array}{c}\text { Neoplasmas } \\
(21,4 \%)\end{array}$ & $\begin{array}{l}\text { Neoplasmas } \\
\quad(16,6 \%)\end{array}$ & $\begin{array}{c}\text { Aparelho Circulatório } \\
(17,8 \%)\end{array}$ & $\begin{array}{c}\text { Neoplamas } \\
(13,4 \%)\end{array}$ \\
\hline $3^{1}$ causa & $\begin{array}{c}\text { Aparelho Respiratório } \\
(7,2 \%)\end{array}$ & $\begin{array}{c}\text { Aparelho Respiratório } \\
(9,7 \%)\end{array}$ & $\begin{array}{c}\text { Neoplasmas } \\
\quad(17,6 \%)\end{array}$ & $\begin{array}{l}\text { Aparelho Respiratório } \\
\qquad(12,2 \%)\end{array}$ \\
\hline $4^{1}$ causa & $\begin{array}{l}\text { Externas } \\
(5,1 \%)\end{array}$ & $\begin{array}{l}\text { Glândulas Endócrinas } \\
\text { Cap. III }(6,6 \%)\end{array}$ & $\begin{array}{l}\text { Externas } \\
(10,6 \%)\end{array}$ & $\begin{array}{l}\text { Afeç̧ões Período } \\
\text { Perinatal }(7,9 \%)\end{array}$ \\
\hline $5^{2}$ causa & $\begin{array}{c}\text { Aparelho Digestivo } \\
(4,6 \%)\end{array}$ & $\begin{array}{c}\text { Aparelho Digestivo } \\
(4,4 \%)\end{array}$ & $\begin{array}{c}\text { Aparelho Respiratório } \\
(8,3 \%)\end{array}$ & $\begin{array}{c}\text { Infecciosas Parasi- } \\
\text { tárias }(7,6 \%)\end{array}$ \\
\hline
\end{tabular}

* Entre parênteses, valores da mortalidade proporcional (\%).

* *efere-se ao período 1979/1981.

\section{TABELA 4}

Coeficientes padronizados de mortalidade segundo sexo, principais causas básicas (Capítulos da CID) e populações de estudo, 1980 (por 10.000 habitantes)

\begin{tabular}{|c|c|c|c|c|c|c|}
\hline \multirow[b]{2}{*}{ Causas básicas } & \multicolumn{2}{|c|}{ Japão } & \multicolumn{2}{|c|}{ Isseis } & \multicolumn{2}{|c|}{ Munic. S. Paulo } \\
\hline & Masc. & Fem. & Masc. & Fem. & Masc. & Fem. \\
\hline $\begin{array}{l}\text { Infecciosas e para- } \\
\text { sitárias }\end{array}$ & 3,4 & 1,7 & 3,1 & 1,5 & 6,9 & 3,4 \\
\hline Neoplasmas & 45,6 & 27,9 & 36,4 & 23,8 & 44,2 & 31,0 \\
\hline Endócrinas* & 2,2 & 2,2 & 5,3 & 9,4 & 9,3 & 11,5 \\
\hline Aparelho circulatório & 77,2 & 70,6 & 73,6 & 75,5 & 130,7 & 112,6 \\
\hline $\begin{array}{l}\text { Aparelho respi- } \\
\text { ratório }\end{array}$ & 16,4 & 10,8 & 17,4 & 13,8 & 27,8 & 17,2 \\
\hline Aparelho digestivo & 10,6 & 6,7 & 9,5 & 6,2 & 14,8 & 8,2 \\
\hline Externas & 9,8 & 5,0 & 10,1 & 3,1 & 15,5 & 4,9 \\
\hline Total & 177,9 & 142,7 & 163,2 & 143,0 & 261,9 & 198,3 \\
\hline
\end{tabular}

* Doenças das glândulas endócrinas, da nutrição e do metabolismo e transtornos imunitários 458 
TABELA 5

Coeficientes padronizados de mortalidade por Neoplasias Malignas (CID-140 a 209) segundo sexo, localização anatômica e populações de estudo, 1980 (por 10.000 habitantes)*

\begin{tabular}{|c|c|c|c|c|c|c|}
\hline \multirow[b]{2}{*}{$\begin{array}{r}\text { Localização } \\
\text { anatômica }\end{array}$} & \multicolumn{2}{|c|}{ Japão } & \multicolumn{2}{|c|}{ Isseis } & \multicolumn{2}{|c|}{ Munic. S. Paulo } \\
\hline & Masc. & Fem. & Masc. & Fem. & Masc. & Fem. \\
\hline Estômago & $\begin{array}{c}14,8 \\
(23,6)\end{array}$ & $\begin{array}{c}7,7 \\
(11,2)\end{array}$ & $\begin{array}{c}12,7 \\
(20,6)\end{array}$ & $\begin{array}{c}6,1 \\
(8,5)\end{array}$ & $\begin{array}{c}7,6 \\
(12,2)\end{array}$ & $\begin{array}{c}4,1 \\
(6,0)\end{array}$ \\
\hline Fígado & $\begin{array}{c}4,5 \\
(7,1)\end{array}$ & $\begin{array}{c}1,8 \\
(2,7)\end{array}$ & $\begin{array}{c}1,9 \\
(2,9)\end{array}$ & $\begin{array}{c}0,4 \\
(0,6)\end{array}$ & $\begin{array}{c}1,6 \\
(2,6)\end{array}$ & $\begin{array}{c}1,0 \\
(1,5)\end{array}$ \\
\hline Pulmão & $\begin{array}{c}7,7 \\
(12,6)\end{array}$ & $\begin{array}{c}2,4 \\
(3,6)\end{array}$ & $\begin{array}{c}6,0 \\
(9,8)\end{array}$ & $\begin{array}{c}1,1 \\
(1,7)\end{array}$ & $\begin{array}{c}7,8 \\
(12,5)\end{array}$ & $\begin{array}{c}2,1 \\
(3,0)\end{array}$ \\
\hline Mama & - & $\begin{array}{c}1,4 \\
(1,8)\end{array}$ & - & $\begin{array}{c}1,0 \\
(1,3)\end{array}$ & - & $\begin{array}{c}4,5 \\
(6,2)\end{array}$ \\
\hline Útero e placenta & 二 & $\begin{array}{c}2,2 \\
(3,1)\end{array}$ & - & $\begin{array}{c}3,1 \\
(4,3)\end{array}$ & $=$ & $\begin{array}{c}3,3 \\
(4,6)\end{array}$ \\
\hline Colo do útero & $\overline{-}$ & $\begin{array}{c}0,7 \\
(0,9)\end{array}$ & - & $\begin{array}{c}1,4 \\
(2,2)\end{array}$ & - & $\begin{array}{c}1,4 \\
(1,9)\end{array}$ \\
\hline Próstata & $\begin{array}{c}0,9 \\
(1,5)\end{array}$ & - & $\begin{array}{c}2,0 \\
(3,3)\end{array}$ & $=$ & $\begin{array}{c}4,2 \\
(6,9)\end{array}$ & $=$ \\
\hline Total & $\begin{array}{c}44,2 \\
(70,4)\end{array}$ & $\begin{array}{c}26,8 \\
(39,0)\end{array}$ & $\begin{array}{c}35,7 \\
(57,3)\end{array}$ & $\begin{array}{c}23,7 \\
(33,9)\end{array}$ & $\begin{array}{c}43,7 \\
(69,2)\end{array}$ & $\begin{array}{c}30,6 \\
(44,3)\end{array}$ \\
\hline
\end{tabular}

* Os valores entre parênteses representam coeficientes de mortalidade padronizados para 50 anos e mais.

e a dos isseis, respectivamente. No sexo feminino, as diferenças se mantêm, acentuando-se entre as japonesas, pois a taxa das isseis é $20,8 \%$ menor que a das mulheres no Japão. Tal risco em São Paulo é $32,8 \%$ menor que o das isseis e $46,8 \%$ menor que o do Japão.

Hipóteses para tais diferenças foram apresentadas por vários autores 5,7 . Alguns fatores de risco, para a maior incidência de câncer de estômago na população do Japão, seriam elementos da dieta tais como vegetais em conserva ("pickles"), peixes desidratados e alimentos exageradamente salgados que, muito precoce e continuamente, são introduzidos na dieta.

Dado que a mortalidade dos isseis é menor que a do Japão, algumas hipóteses podem ser aventadas, tais como, mudança gradativa nos hábitos culturais, redundando em transformação da dieta oriental e adoção paulatina do padrão alimentar do local de destino e presença de riscos competitivos de morte representados pelas doenças es- pecíficas de São Paulo, atuando mais precocemente. Para São Paulo, o menor risco seria, ainda, decorrente da menor incidência (50\% menor) ${ }^{24}$.

Os coeficientes padronizados de mortalidade por câncer do pulmão, no Japão e em São Paulo, têm valores próximos $(7,7$ e 7,8 por dez mil homens, respectivamente); entre os isseis o valor é igual a 6,0 por dez mil homens, $23 \%$ menor. Analisando os coeficientes específicos de mortalidade por câncer de pulmão, algumas diferenças acontecem: até os 70 anos, no sexo masculino e até os 60 anos, nas mulheres, são sempre maiores em São Paulo, quando, então, são suplantados pelos do Japão.Tal fato sugere que, sendo as incidências semelhantes ${ }^{24}$, haveria diagnóstico mais precoce no Japão, e como conseqüencia, uma maior sobrevivência.

$O$ coeficiente padronizado de mortalidade por câncer de mama em São Paulo é, 2,2 vezes maior do que o do Japão. Fato esperado, pois o Japão apresenta um dos mais baixos coeficientes de incidencia no mundo (um terço do referente a São $\mathrm{Pa}^{\prime}$ 'o) ${ }^{24}$. As 
isseis apresentam valor mais baixo, sendo o coeficiente igual a um óbito por dez mil.

Possiveis fatores de risco que estariam atuando diferentemente nestas populações remetem à existência de alta correlação positiva entre consumo de dietas ricas em gorduras e incidência de câncer de mama e à hipótese relativa a diferenças nas constituiçðes anatômica e hormonais. Como no Japão a dieta é comparativamente uma das menos ricas em gorduras, as mulheres estariam mais protegidas. Pike ${ }^{21}$ comenta que as japonesas apresentam menor incidência de câncer de mama do que as mulheres ocidentais, em função de terem a menarca mais tardiamente, ciclos menstruais mais longos. Buell ${ }^{2}$ descreveu incidências crescentes de câncer de mama em mulheres de ascendência japonesa, em geraçôes sucessivas, na América. Atribuiu a mudança ao maior consumo de macronutrientes, refletindo em aumento de altura e peso dessas mulheres.

$\mathrm{Hems}^{8}$ mostrou existir correlação positiva entre a tendência secular do aumento do consumo de laticínios e a maior mortalidade por câncer de mama. Comentou serem paralelas as tendências da mortalidade e de aumento de consumo das gorduras de laticínio, proteínas animais e açúcares, entretanto, o aumento da mortalidade apresenta-se com uma defasagem de dez a vinte anos posterior ao início do aumento de consumo.

Ao serem comparados os coeficientes por câncer de mama, há tendência de excesso para São Paulo, aumentando em função das idades. Assim, dos 35 aos 39 anos o risco é $100 \%$ maior, dos 60 aos 64 anos passa a ser $200 \%$ maior e, na faixa de 70 a 74 anos, o coeficiente é $300 \%$ maior do que o do Japão.

Os óbitos de câncer de mama das isseis concentram-se em poucas faixas etárias, mas verifica-se que, em cada uma delas, o coeficiente é maior do que o do Japão. Pode-se cogitar em atuação de fatores ambientais interagindo com os genéticos, sendo a possível mudança nos hábitos alimentares a explicação para o aumento de risco das isseis.

O coeficiente padronizado de mortalidade por câncer de próstata é $360 \%$ maior em São Paulo do que no Japão. Os isseis apresentam valor intermediário, sendo $120 \%$ maior que o do Japão e $52 \%$ menor que o coeficiente dos residentes em Såo Paulo.

Tal fato desperta a atenção para a mudança de padrāo nos migrantes. Fatores possíveis de risco estariam mais relacionados à ação do ambiente do que aos fatores genéticos. Uma hipótese para tal discrepância nos valores dos riscos de morrer, além da conhecida maior taxa de incidência em São Pau$10^{24}$, seria a diferença de momento do diagnóstico. Quanto mais precoce (o estadio inicial da doença permite melhor prognóstico devido a tratamento cirúrgico e radioterápico menos agressivo ao in- divíduo) possibilita maior sobrevida. $\mathrm{Pike}^{20} \mathrm{co}-$ menta que pessoas com cirrose de fígado têm taxas mais baixas de câncer de próstata e a possível explicação seria o fato de o álcool deprimir o nivel de testosterona circulante. Como é alto o consumo de álcool no Japão, talvez este seja um possível fator de proteção para os seus habitantes.

Diabetes Mellitus - Uma outra causa básica de morte com comportamento bem distinto nas populaçôes de estudo é o diabetes. Assim, os coeficientes de mortalidade masculina padronizados são de 1,9 por dez mil homens no Japão, 3,4 por dez mil homens isseis e 7,6 por dez mil homens em São Paulo. Portanto, o valor estimado em São Paulo é quatro vezes o do Japão e mais de duas vezes o dos isseis. Estes mesmos índices, para as mulheres, são de 1,9 por dez mil mulheres no Japão, 7,2 por dez mil isseis e 9,9 por dez mil mulheres residentes em São Paulo; portanto este último é $425 \%$ maior que o do Japão e somente $38 \%$ maior que o das isseis. Estas diferenças marcantes fazem com que algumas hipóteses ocorram, relacionadas a fatores de risco possiveis.

Trabalhos ${ }^{18}$ mostram que em algumas sociedades o diabetes associa-se freqüentemente à obesidade e,em outras, à desnutrição. Mencionam também o fato de que em comunidades com alta incidência de doenças infecciosas há também alta prevalência de diabetes. Haveria, então, interação de fatores ambientais em indivíduos geneticamente suscetíveis que, atuando conjuntamente, determinariam a evolução da doença. Provavelmente, estes fatores estariam presentes em São Paulo, desencadeando a alta incidência de diabetes e conseqüente alta mortalidade que estão sujeitos seus residentes.

Um outro ponto a ser lembrado, além dos fatores de risco biológicos, é o que se refere à possível diferença de qualidade e de disponibilidade da assistência médica, das duas áreas, que redundaria em maior mortalidade, em São Paulo.

Analisando a mortalidade nos vários grupos etários, as diferenças são mais visíveis, pois já a partir dos 30 anos os coeficientes em São Paulo são maiores, acentuando-se nas faixas etárias de 50 anos e mais (Figs. 1 e 2). Chama a atenção a sobremortalidade femina, pois no Japão não há e, em São Paulo, o risco das mulheres é $30 \%$ maior que o dos homens; entre isseis, a taxa das mulheres é $110 \%$ maior. Assim, os isseis, especialmente as mulheres, estariam adotando alguns hábitos correntes em São Paulo e assumindo os riscos de adoecer e de morrer por diabetes, desta cidade.

Doenças do Aparelho Circulatório - O risco de morrer por Doenças do Aparelho Circulatorio (DAC) necessita ser analisado à luz do comportamento de seus componentes (agrupamento de causas) pois cada um apresenta-se diferentemente, oferecendo contrastes interessantes. 


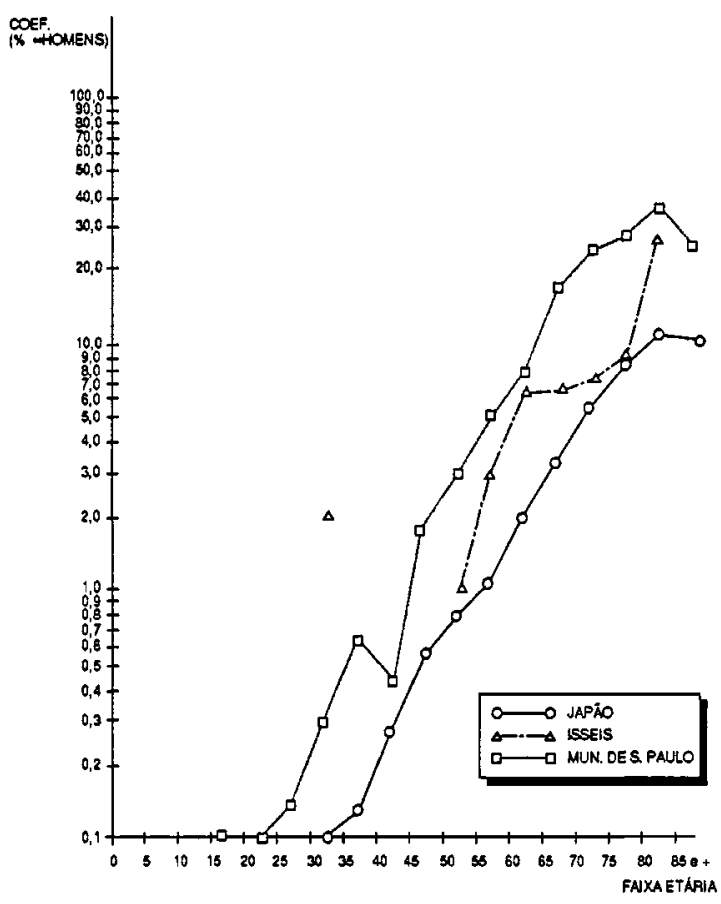

Fig. 1 - Coeficientes de mortalidade por diabetes mellitus segundo populaçōes de estudo e faixa etária, 1980 (por 10.000 homens).

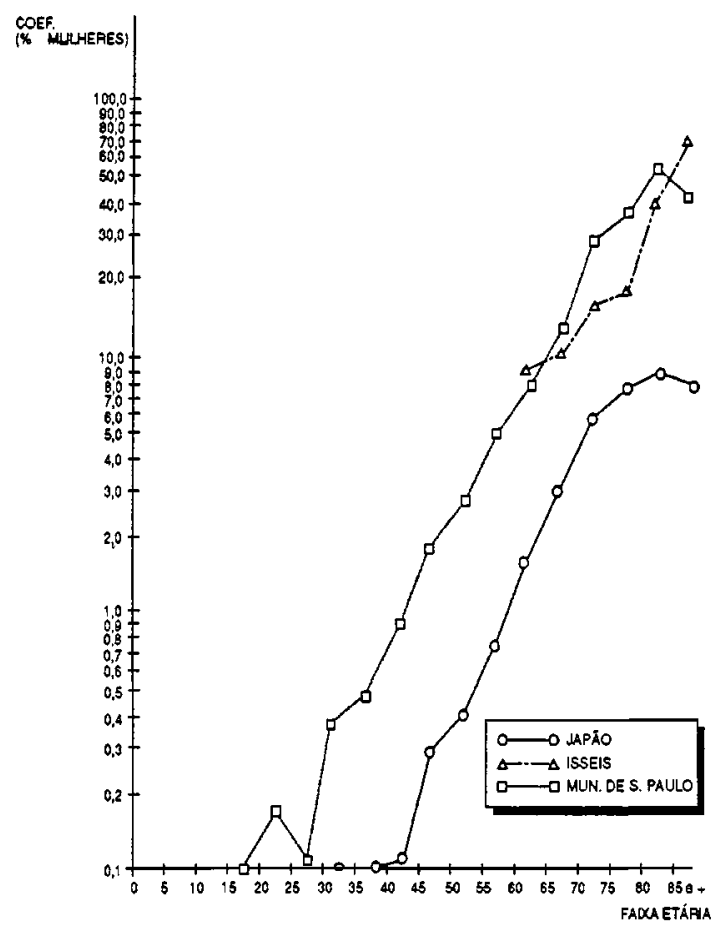

Fig. 2 - Coeficientes de mortalidade por diabetes mellitus segundo populações de estudo e faixa etária, 1980 (por 10.000 mulheres).
As alterações ateroscleróticas das artérias coronarianas que levam às DIC são as grandes responsáveis pelas diferenças de risco de morrer por DAC entre os residentes no Japão e em São Paulo (Tabela 6).

As taxas padronizadas de mortalidade por DIC em Sāo Paulo são quatro vezes as do Japão, em ambos os sexos. Os isseis posicionam-se em nível intermediário pois o risco é o dobro do apresentado pelo Japão e a metade do valor de São Paulo, para os homens. A taxa para as mulheres isseis é 2,5 vezes a do Japão e igual a $60 \%$ do valor de São Paulo (Fig. 3). A partir dos 40 anos, o risco de morrer por DIC, para os homeṇs de São Paulo, começa a se destacar e é sete vezes maior do que o do Japão, mostrando quão precocemente a mortalidade inicia sua atuação ( 8,1 por dez mil homens). Aos 50 anos, a taxa é cinco vezes maior; aos 65 anos é quatro vezes e, acima de 75 anos, chega a ser três vezes ao valor do Japão.

$O$ risco de morrer por DIC dos isseis, aos 50 anos, é 3,6 vezes o do Japão; aos 65 anos é 2,3 vezes e aos 75 anos é 1,5 vezes o valor do Japão. Portanto os migrantes tendem a ter risco mais próximo ao do local de destino (Fig. 4).

As mulheres de São Paulo aos 50 anos têm risco de morrer por DIC seis vezes o das mulheres do Japão; a partir dos 60 anos, este torna-se quatro vezes. As taxas das isseis, mais próximas às de São Paulo oscilam de tal forma que, em torno dos 50 anos, a taxa em São Paulo é 100\% maior e, para as mais idosas, apenas, $50 \%$ maior que a das isseis (Fig. 5).

Gordon ${ }^{5}$ mostrou estes mesmos contrastes, relativamente à população branca e à de migrantes japoneses residentes na Califórnia (EUA) e à população do Japão.

Diante dessas constatações, a mortalidade por DIC elevada, em São Paulo, intermediária entre os migrantes e baixa no Japão, surge o interesse em conhecer-se quais seriam os motivos que permeiam estas diferenças.

Seriam os fatores genéticos menos eficientes do que os ambientais? E reconhecido que ambos, possivelmente, são responsáveis pela ocorrência das DIC.

Ostfeld ${ }^{19}$ considera alguns fatores definitivos para o aumento do risco de ter DIC (altas lipidemia e glicemia, hábito de fumar, baixa capacidade vital, obesidade) enquanto que outros são tidos como possiveis (vida sedentária, dieta rica em gordura animal, "stress", ansiedade e tensão).

Pode-se levantar a hipótese de que, com padrão genético tal qual de seus compatriotas, os isseis estariam expostos a ação de novos fatores ambien- 
TABELA 6

Coeficientes padronizados de mortalidade por doenças do Aparelho Circulatório (Capítulo VII) segundo sexo, agrupamento da CID e populações de estudo, 1980 (por 10.000 habitantes).*

\begin{tabular}{|c|c|c|c|c|c|c|}
\hline \multirow[b]{2}{*}{ Agrupamento } & \multicolumn{2}{|c|}{ Japão } & \multicolumn{2}{|c|}{ Isseis } & \multicolumn{2}{|c|}{ Munic. S. Paulo } \\
\hline & Masc. & Fem. & Masc. & Fem. & Masc. & Fem. \\
\hline $\begin{array}{c}\text { D. Isquêmica } \\
\text { do Coração }\end{array}$ & $\begin{array}{c}13,4 \\
(21,8)\end{array}$ & $\begin{array}{c}9,9 \\
(15,0)\end{array}$ & $\begin{array}{c}27,2 \\
(43,9)\end{array}$ & $\begin{array}{c}24,4 \\
(36,5)\end{array}$ & $\begin{array}{c}53,7 \\
(85,8)\end{array}$ & $\begin{array}{c}39,2 \\
(59,4)\end{array}$ \\
\hline Outras formas & $\begin{array}{c}17,1 \\
(27,3)\end{array}$ & $\begin{array}{c}16,7 \\
(25,3)\end{array}$ & $\begin{array}{c}5,9 \\
(9,9)\end{array}$ & $\begin{array}{c}7,9 \\
(12,1)\end{array}$ & $\begin{array}{c}20,4 \\
(32,3)\end{array}$ & $\begin{array}{c}20,2 \\
(29,9)\end{array}$ \\
\hline D. Cerebrovasculares & $\begin{array}{c}40,4 \\
(65,7)\end{array}$ & $\begin{array}{c}36,9 \\
(56,0)\end{array}$ & $\begin{array}{c}30,2 \\
(48,7)\end{array}$ & $\begin{array}{c}32,2 \\
(48,4)\end{array}$ & $\begin{array}{c}35,1 \\
(55,6)\end{array}$ & $\begin{array}{c}32,7 \\
(48,5)\end{array}$ \\
\hline $\begin{array}{l}\text { Aparelho } \\
\text { Circulatório }\end{array}$ & $\begin{array}{c}77,2 \\
(125,0)\end{array}$ & $\begin{array}{c}70,6 \\
(107,1)\end{array}$ & $\begin{array}{c}73,6 \\
(119,5)\end{array}$ & $\begin{array}{c}75,5 \\
(113,5)\end{array}$ & $\begin{array}{c}130,7 \\
(207,8)\end{array}$ & $\begin{array}{r}112,6 \\
(168,4)\end{array}$ \\
\hline
\end{tabular}

* Os valores entre parênteses representam coeficientes de mortalidade padronizados para 50 anos e mais.

tais. Dada a aculturação, seus hábitos tornam-se mais ocidentais, com aceitação e utilização de uma dieta mais rica em gordura animal e açúcares. Mudanças na qualidade de vida também podem estar ocorrendo, com vida mais sedentária e dada a condição urbana, mais ansiedade e tensão. Reed e col. ${ }^{2}$ dizem que processos psicossociais podem alterar o risco de desenvolver as DIC, tais como a mobilidade social e vida com eventos "stressantes".

Em 1968, os isseis de São Paulo mostravam uma situação diferente ${ }^{6}$, sendo que o peso das DIC era bem menor que o das DCV. Em 1980, as mortes masculinas por DCV são apenas $10 \%$ a mais do que as por DIC, possibilitando pensar-se que, após doze anos e estando os isseis mais velhos e sem a chegada de novos migrantes, teriam sofrido aculturação. Dessa forma aproximam-se, em termos de risco de morrer, da população que os recebeu, pois esta possível mudança estaria associada às DIC por causa de sua associação com outros fatores de risco ${ }^{22}$.

Quanto às DCV, o padrão é diferente (Tabela 4) pois o risco no Japão é $33 \%$ maior do que o dos isseis e $15 \%$ maior que o de São Paulo.

Entre as mulheres, os contrastes são menores, a diferença de taxa entre as residentes no Japão e as isseis é da ordem de $15 \%$ a mais para as do Japão. Comparando as residentes em São Paulo e as isseis não há quase diferença pois os valores são, respectivamente, 32,7 e 32,2 por dez mil mulheres.

As taxas masculinas por idade são maiores até os 60 anos em São Paulo, a partir daí são mais altas no Japão. Os isseis até os 65 anos têm valores 462 intermediários e, após apresentam os menores valores. As mulheres têm padrão diferente, isto é, os riscos são maiores em São Paulo até 70 anos mas, para as mais idosas, o risco é maior no Japão. As isseis têm valores intermediários entre 60 e 75 anos e, nas demais idades, têm os menores coeficientes.

Tais consideraçōes permitem supor que alguns fatores estão tornando a morte mais precoce em São Paulo, relativamente ao Japão. Fazem crer que haja, por parte das autoridades de saúde, uma maior preocupação com controle da hipertensão na população do Japão, dado o grande problema que estas doenças cerebrovasculares representam para seus habitantes.

Excluindo-se a hipertensão arterial, discute-se muito sobre os principais fatores de risco das DCV. Alguns estudos realizados no Japão mostram que a mortalidade por esse agravo estaria associada positivamente ao consumo de dietas ricas em alguns alimentos como arroz e raízes, pastas e molho de soja e peixes salgados (dieta tradicional). Apontam a existência de associação negativa com dietas profusas em trigo, manteiga/margarina, carne de boi e ovos, portanto, dietas tipicamente ocidentais. Concluem que seus resultados mostram a pertinência do excesso de consumo de sal atuando como fator que aumentaria a pressão arterial e levando a maior risco de DCV. Detectaram-se também maior consumo de álcool e menor taxa de colesterol, no Japão ${ }^{16}$.

Verifica-se que os riscos de morrer por DCV dos isseis tendem a se aproximar aos de São Paulo, afastando-se dos valores dos japoneses. Tal comportamento suscita algumas suposições e faz pensar que as DCV não estariam ligadas a carac- 


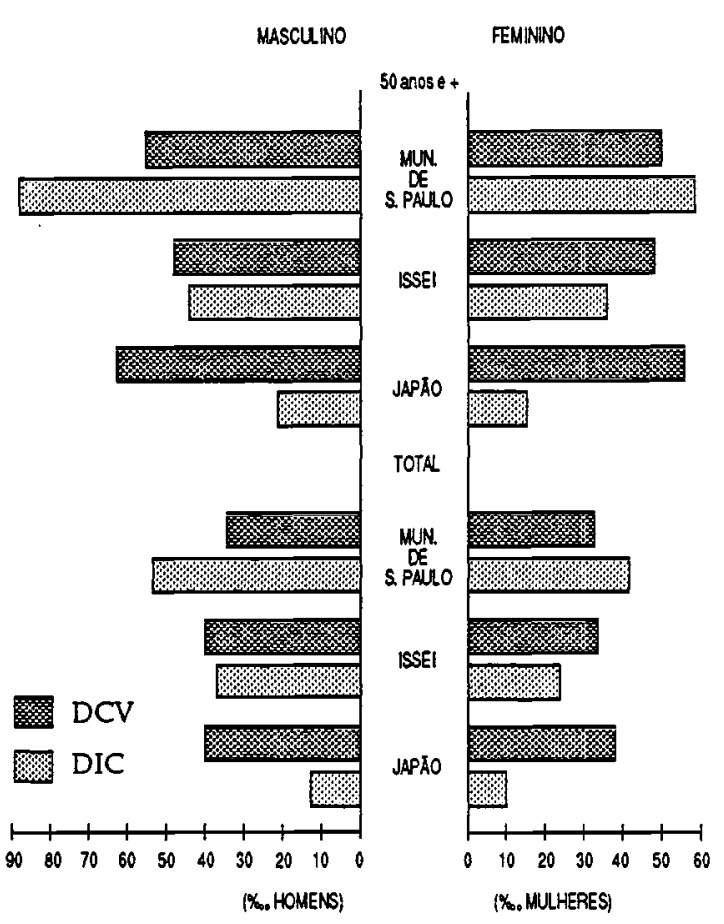

Fig. 3 - Coeficientes padronizados de mortalidade por doenças cerebrovasculares e doenças isquêmicas do coração segundo sexo e populações de estudo, 1980 (por 10.000 habitantes).

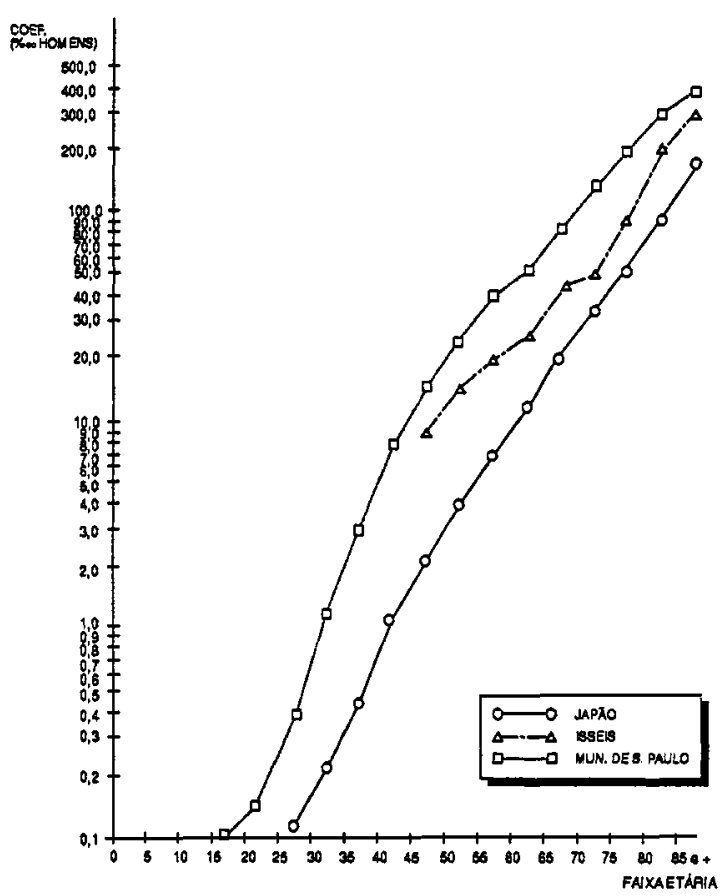

Fig. 4 - Coeficientes de mortalidade por doenças isquêmicas do coração segundo populaçōes de estudo e faixa etária, 1980 (por 10.000 homens).

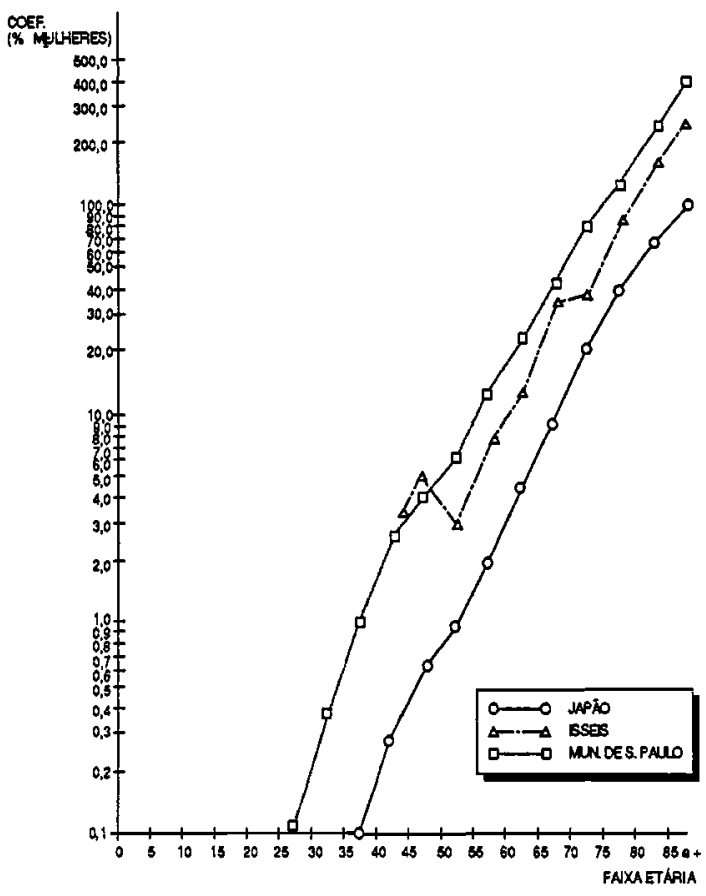

Fig. 5 - Coeficientes de mortalidade por doenças isquêmicas do coração segundo populações de estudo e faixa etária, 1980 (por 10.000 mulheres).

terísticas raciais mas estariam na dependência de fatores do meio ambiente. Assim, os migrantes estariam expostos a riscos competitivos de outras causas de morte mais comuns em São Paulo (DIC, Causas Externas, Doenças Infecciosas) e teriam adotado alguns hábitos correntes em São Paulo, relativos a alimentação mais ocidental, com menor consumo de sal.

Causas Externas de Lesôes e Envenenamentos Do ponto de vista da mortalidade proporcional, no sexo masculino, as causas externas posicionam-se em terceiro lugar, no Japão; em São Paulo, assumem o segundo posto e entre os isseis, a quarta principal causa de morte.

As diferenças detectadas tornam-se mais claras ao analisar-se a mortalidade padronizada por causas externas segundo alguns tipos (Tabela 7). Assim, no Japão, são os suicídios a causa mais im. portante, em ambos os sexos. Em São Paulo, são os acidentes de trânsito de veículo a motor que assumem a liderança, com risco três vezes aquele do Japão. Os isseis sofrendo ação do mesmo ambiente, aproximam-se de São Paulo.

O risco masculino de morrer por suicídio, no Japão, é duas vezes maior que o valor em São Paulo; entre as mulheres o valor das japonesas é cinco vezes o de São Paulo. Os homicídios, representando a ação da violência urbana, assumem valores 


\section{TABELA 7}

Coeficientes padronizados de mortalidade por Causas Externas de Lesðes e Envenenamento segundo sexo, agrupamento da CID e populaçōes de estudo, 1980 (por 10.000 habitantes).*

\begin{tabular}{|c|c|c|c|c|c|c|}
\hline \multirow[b]{2}{*}{ Agrupamento } & \multicolumn{2}{|c|}{ Japão } & \multicolumn{2}{|c|}{ Isseis } & \multicolumn{2}{|c|}{ Munic. S. Paulo } \\
\hline & Masc. & Fem. & Masc. & Fem. & Masc. & Fem. \\
\hline $\begin{array}{l}\text { Acid. de Trâns. } \\
\text { Veíc. a Motor }\end{array}$ & $\begin{array}{c}2,07 \\
(2,61)\end{array}$ & $\begin{array}{c}0,75 \\
(0,99)\end{array}$ & $\begin{array}{c}4,89 \\
(6,46)\end{array}$ & $\begin{array}{c}1,53 \\
(2,34)\end{array}$ & $\begin{array}{l}6,82 \\
(8,20)\end{array}$ & $\begin{array}{c}2,25 \\
(2,91)\end{array}$ \\
\hline Suicidios & $\begin{array}{c}3,46 \\
(3,90)\end{array}$ & $\begin{array}{c}2,27 \\
(2,87)\end{array}$ & $\begin{array}{c}1,13 \\
(1,46)\end{array}$ & $\begin{array}{c}0,85 \\
(0,43)\end{array}$ & $\begin{array}{c}1,21 \\
(1,50)\end{array}$ & $\begin{array}{c}0,50 \\
(0,57)\end{array}$ \\
\hline Homicidios & $\begin{array}{c}0,11 \\
(0,09)\end{array}$ & $\begin{array}{c}0,06 \\
(0,06)\end{array}$ & $\begin{array}{c}1,02 \\
(0,84)\end{array}$ & $\begin{array}{c}0,14 \\
(0,21)\end{array}$ & $\begin{array}{c}2,76 \\
(1,78)\end{array}$ & $\begin{array}{c}0,17 \\
(0,07)\end{array}$ \\
\hline $\begin{array}{l}\text { Causas } \\
\text { Externas }\end{array}$ & $\begin{array}{c}9,78 \\
(12,29)\end{array}$ & $\begin{array}{c}5,02 \\
(6,71)\end{array}$ & $\begin{array}{c}10,05 \\
(12,70)\end{array}$ & $\begin{array}{c}3,07 \\
(3,83)\end{array}$ & $\begin{array}{c}15,53 \\
(16,83)\end{array}$ & $\begin{array}{c}4,89 \\
(6,24)\end{array}$ \\
\hline
\end{tabular}

- Os valores entre parênteses representam coeficientes de mortalidade padronizados para 50 anos e mais.

diferentes, nas duas áreas; em São Paulo, o risco masculino é 25 vezes o do Japão.

O suicídio no Japão atingiu seus mais altos coeficientes na década de 50, dadas as dificuldades do período pós-guerra, declinando depois. As idades mais frequientes de ocorrência são as mais velhas e um pequeno pico era notado na faixa de 20 a 29 anos. Muitas vezes havia indícios de pactos levando a atos conjuntos (enamorados, pais/ filhos) e de idosos que se sentiam como ônus econômico acentuado para os seus filhos. As razões dos jovens estão muito ligadas aos resultados escolares e necessidade de sucesso em exames. Para as adolescentes, é citado o problema relativo ao momento do casamento, pois era esperado que este acontecesse precocemente, caso contrário haveria desprestígio para a família, tal qual a falha na vida acadêmica. Para os japoneses, há grande respeito cultural ao suicídio, da mesma forma que à vida9, diferente portanto da cultura ocidental, onde para o catolicismo e judaísmo, por exemplo, 0 suicídio é um ato criticável.

As mulheres japonesas apresentam coeficientes de mortalidade por suicídio que variam de 2,5 a 5 vezes os de São Paulo e as diferenças acentuam-se nas mais idosas pois, a partir dos 70 anos, as taxas, no Japão, chegam a ser seis vezes maiores que as de São Paulo (Figs. 6 e 7 ).

Os isseis apresentam riscos que oscilam entre os valores das duas áreas; entretanto, o padrão tende a se aproximar mais ao existente no Japão do que aquele em São Paulo.

Os coeficientes masculinos de mortalidade por 464 homicídios só são maiores no Japão até a idade de 10 anos, quando então os valores de São Paulo os ultrapassam de forma acentuada; como exemplo, na faixa etária de 15 a 19 anos a taxa em São Paulo é 162 vezes maior, dos 20 aos 24 chega a ser 224 vezes maior. Até os 65 anos giram em torno de 30 a 40 vezes os valores referentes ao Japão (Fig. 8). Para as mulheres, as diferenças são menores.

Os aspectos sócio-econômicos e culturais tão distintos, apresentados nas duas áreas de estudo, podem ser responsabilizados pelos diferentes níveis de mortalidade por violência que se observam. Os migrantes, sofrendo ação dos fatores ambientais, assemelham-se, em termos de risco de morrer por homicídio, ao padrão da localidade onde vivem $e$, havendo um abandono paulatino de alguns valores culturais correntes no seu país de nascimento, passam a aceitar novos valores, prevalentes na área que adotaram, tendo o seu coeficiente de mortalidade por suicídio diminuído, em relação ao Japão.

\section{4 - CONSIDERAÇÕES FINAIS}

Os resultados aqui obtidos permitiram observar comportamentos distintos na mortalidade das populações de estudo e, como conseqüência, algumas hipóteses e questões emergem.

Verificou-se que o nível de saúde em São Paulo, medido por meio de coeficientes padronizados de mortalidade, é inferior ao do Japão e o dos isseis assemelha-se mais ao Japão.

Algumas diferenças foram detectadas na ordenação das causas quando da mortalidade proporcio- 


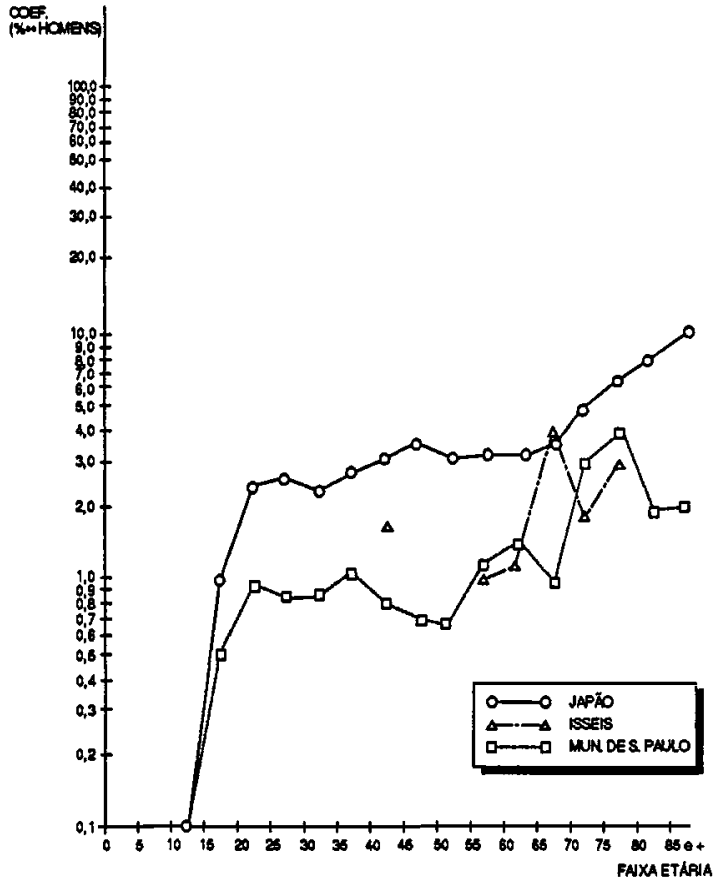

Fig. 6 - Coeficientes de mortalidade por suicídios segundo populações de estudo e faixa etária, 1980 (por 10.000 homens).

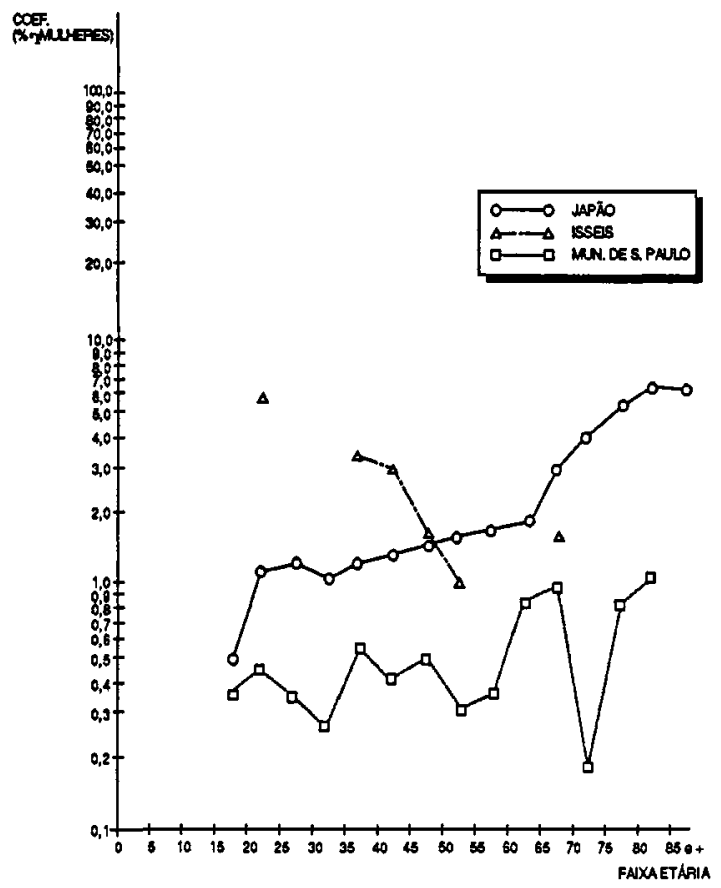

Fig. 7 - Coeficientes de mortalidade por suicídios segundo populações de estudo e faixa etária, 1980 (por 10.000 mulheres).

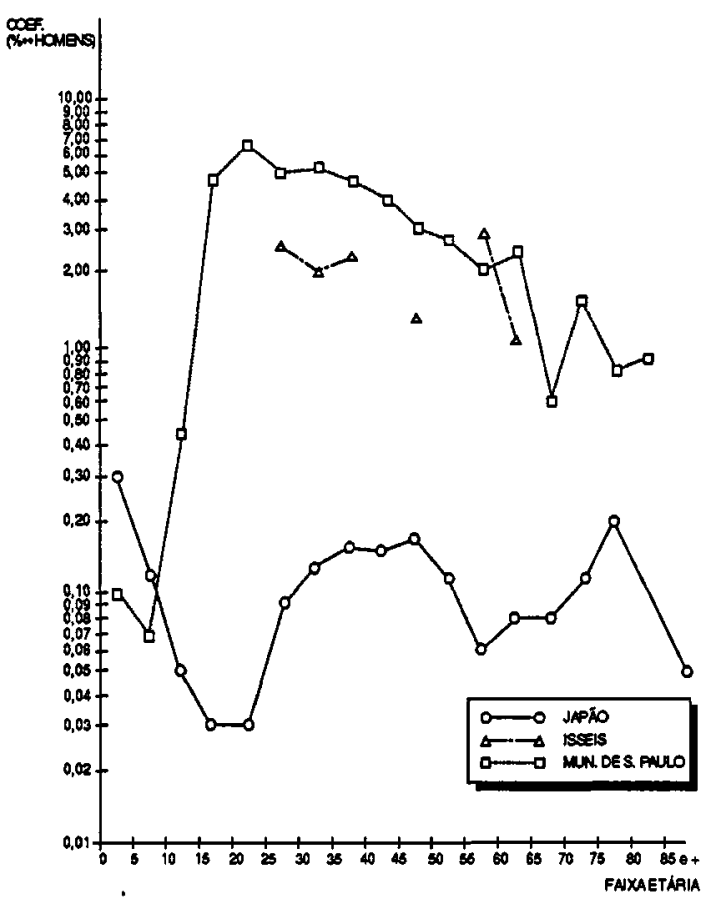

Fig. 8 - Coeficiente de mortalidade por homicídios segundo populaçōes de estudo e faixa etária, 1980 (por 10.000 homens).

nal, entretanto, as intensidades de risco, em cada uma das populações, são bastante distintas. São Paulo apresenta os maiores valores e os isseis apresentam valores intermediários entre os padrões do Japão e de São Paulo, no caso das doenças endócrinas, das doenças do aparelho respiratório, em ambos os sexos, e das doenças do aparelho circulatório, no caso das mulheres. Nas demais causas, os isseis apresentam os menores coeficientes.

Diferenças importantes surgem em algumas causas específicas. $O$ câncer de estômago apresenta os maiores riscos de morte para o Japão; os isseis, apesar de terem risco um pouco menor, ainda se afastam do valor de São Paulo. Os coeficientes de - mortalidade por câncer de próstata e de mama são muito baixos no Japão, entretanto os isseis perdem a resistência a estes agravos e têm riscos mais próximos aos de São Paulo.

Diabetes, principalmente no sexo feminino, é outra causa que faz pensar na experiência vivenciada pelos migrantes e seus descendentes, aproximando-os, em termos de mortalidade, aos valores da população do local de destino.

Quanto às DAC, as diferenças são marcantes. No Japão, há disparidade entre os valores das DIC e das DCV, as primeiras com taxas um terço do valor das últimas. Os isseis, ao migrar, perdem 
o contraste acentuado, não às custas de um menor risco de morrer por DCV, mas sim, pelo aumento da taxa por DIC, fazendo com que se aproximem do padrão de São Paulo, onde as DIC têm risco 1,5 vezes o valor das $D C V$.

A literatura tem mostrado que o padrão de mortalidade dos migrantes tende a se aproximar ao do local de destino. Em São Paulo, com os isseis, isto também ocorreu e, como conseqüência, indagações e suposiçōes surgiram para uma possível explicação desses efeitos detectados. Mudanças de hábitos e costumes dos migrantes devem ter acontecido e, como decorrência, mudanças da prevalência dos fatores biológicos de risco.

Justifica-se, então, o prosseguimento de investigação, tentando detectar e quantificar as mudanças socioculturais experimentadas por eles, depois de sua chegada a São Paulo, pois é importante destacar que este tipo de estudo, apesar de descritivo, evidenciou a predominancia de atuação de fatores de risco ambientais sobre os genéticos.

GOTLIEB , S. L. D. [Mortality in migrants - Japanese residents in the City of S.Paulo, Brazil, 1980]. Rev. Saúde públ., S. Paulo, 24: 453-67, 1990.

ABSTRACT: The mortality patterns of Japanese migrants (issei) and their descendants (nissei/ sansei) resident in the City of S.Paulo, Brazil, are compared with those of their native country (Japan) and their place of adoption (S. Paulo), in 1980. The mortality data were obtained from death certificates for the issei and nissei/sansei populations and from official tabulations for deaths in Japan and S.Paulo. The population estimates were based upon the S.Paulo and Japanese censuses. The agestandardized populations were calculated according to the Jowett method. The five leading causes of death were basically the same for these populations under study. S.Paulo residents had the highest age-standardized mortality rates, except as regards deaths due to neoplasms, higher in Japan. The issei population (both sexes) presented intermediate values for deaths due to endocrine, nutritional, and metabolic diseases and diseases of the respiratory system; the female migrants also showed an intermediate rate for deaths due to diseases of the circulatory system. For the other causes, the lowest risk of dying was that registered for the issei population. The comparisons of the rates for cancers of stomach, breast, prostate, diabetes mellitus, ischaemic heart diseases, cerebrovascular ctiseases, homicide and suicide resulted in the detection of a possible transition experienced by the issei population, leading to the belief that the issei pattern of mortality is showing a deviation from the Japanese pattern and resembles that of S.Paulo. Since social and cultural changes are thought to be occurring among the migrants, one might argue that the role of environmental factors (including diet) is more important than the role of genetic factors in the incidence of and mortality due to these diseases.

KEYWORDS: Mortality. Cause of death. Ethnic groups. Japan, ethnology.

\section{REFERÊNCIAS BIBLTOGRÁFICAS}

\section{ANUÁRIO ESTATÍSTICO DO ESTADO DE SÃo PAULO:} 1980. São Paulo, Fundação SEADE, 1981.

2. BUELL, P. Changing incidence of breast cancer in Japanese American women. J. nat. Cancer Inst., 51 : $1479-83,1973$.

3. FLEISS, J. L. Statistical methods for rates and pro. portions. 2nd ed. New York, John Wiley, 1981.

4. FUNDAÇÃO IBGE. Censo demográfico; Brasil: dados gerais migração, instrução, fecundidade, mortalidade. Rio de Janeiro, 1983. v.1, t.4, n.1. (99 Recenseamento Geral do Brasil, 1980).

5. GORDON, T. Further mortality experience among Japanese Americans. Publ. Hlth Rep., 82: 973-84, 1967.

6. GOTLIEB, S. L. D. Alguns aspectos da mortalidade entre japoneses e seus descendentes residentes no $\mathrm{Mu}$ nicípio de São Paulo, Brasil. Rev. Saúde públ., S. Paulo, 8: 411-20, 1974.
7. HAENSZEL, W. Report of the working group on studies of cancer and related diseases in migrant population. Int. J. Cancer, 4: 364-71, 1969.

8. HEMS, G. Association between breast cancer mortality rates, child bearing and diet in the United Kingdom. Brit. J. Cancer, 41: 429-36, 1980.

9. IGA, M. et al. Suicide in Japan. Soc. Sci. Med., 12A: 507-16, 1978.

10. JAPAN MTISTRY OF HEALTH AND WELFARE. Vital statistics: 1980 . Tokyo, 1982.

11. KLEINBAUM, D. G. et al. Epidemiologic research. Belmont, Calif., Lifetime Learning Publ., 1982.

12. KURODA, T. M. The demographic transition in Japan. Soc. Sci. Med., 12A: 451-7, 1978.

13. LAURENTT, R. et al. Estatísticas de saúde. Sảo Paulo, EPU/Ed.USP, 1985. 
14. LEVY, M. S. F. O papel da migração intemacional na evolução da população brasileira (1872 a 1982). Rev. Saúde públ., S. Paulo, 8 (supl.): 49-90, 1974.

15. MORRIS, J. N. Uses of epidemiology. 3rd ed. Edinburg. Churchill Livingstone, 1975.

16. OMURA, T. et al. Geographical distribution of cerebro vascular disease mortality and food intakes in Japan. Soc. Sci. Med. 24: 401-7, 1987.

17. ORGANIZAÇÃO MUNDIAL DA SAUDE. Classificação estatística internacional de doenças, lesóes e causas de óbito: $9^{2}$ revisão, 1975. São Paulo, Centro da OMS para Classificação de Doenças em Português, 1978. v. 1.

18. ORGANZACION MUNDIAL DE LA SALUD. Comite de Expertos en Diabetes Sacarina, Ginebra, 1979. Segundo informe. Ginebra, 1980. (Serie de Informes Técnicos, 646).

19. OSTFELD, A. M. The interaction of biological and social variables in cardiovascular diseases. Milbank mem. Fd Quart., 45: (2pt. 2): 13-8, 1967.

20. PIKE, M. C. Endogenous hormone. In: Vessay, M. P. \& Gray, M., ed. Cancer risks and prevention. Oxford, Oxford University Press, 1985. p. 195.
21. PIKE, M. C. Age related factors in cancers of the breast, ovary and endometrium. J. chron. Dis., 40: (Suppl.2) : 595-695, 1987.

22. REED, D. M. et al. Acculturation and coronary heart disease among Japanese men in Hawaii. Amer. $J$. Epidem., 115: 891-905, 1982.

23. REID, D. D. Intemational studies in epidemiology. Amer. J. Epidem., 102: 469-76, 1975.

24. SEGI, M. Graph presentation of cancer incidence by site and by area and population. Nagoya, Segi Institute of Cancer Epidemiology, 1977.

25. STATISTICS BUREAU PRIME MINISTER'S OFFICE. Population of Japan: 1980 population Census of Japan. Tokyo, 1982. (Abriged Report Series $n^{2} 1$ )

26. SVANBORG, A. et al. Comparison of ecology, ageing and state of health in Japan and Sweden : the present and previous leaders in longevity. Acta med. scand., 218 : 5-17, 1985.

Recebido para publicaçăo em 16/02/1990

Reapresentado em 22/06/1990 Aprovado para publicação em 02/07/1990 